\section{Litter quality changes during decomposition investigated by thermal analysis}

\author{
Paola Gioacchini ${ }^{(1)}$, Daniela Montecchio ${ }^{(1)}$, Erika Ferrari ${ }^{(2)}$, Claudio \\ Ciavatta ${ }^{(1)}$, Andrea Masia ${ }^{(1)}$, Elisabeth George ${ }^{(3)}$, Giustino Tonon ${ }^{(3)}$
}

The litter decomposition process depends on the litter chemical composition, especially the ratio between more labile compounds, cellulose, and the recalcitrant lignin and waxes. Their determination is crucial to predict the process, though lignin measurement presents some limitations due to drawbacks of the different methods. Thermal analysis has been successfully applied to several organic materials in order to obtain quali-quantitative information of the chemical structure of the sample. In this work TG-DTA was used in a shortterm litter decomposition study of two broadleaf forest stands of contrasting ages, and the results were compared to those obtained with a chemical method (Klason's method) commonly used to quantify cellulose and lignin. TGDTA was applied to the litter and to the cell walls (CW) extracted from the lit ter, whose cellulose and lignin content was determined using the Klason's method. When applied to litter, thermal analysis showed a weak correlation with the Klason's method, though it allowed the detection of the dynamics of waxes, that increased during the decomposition and could influence the later stages of the process. Contrastingly, a good correlation between cellulose and lignin determined with the two methods was found when TG-DTA was applied to the CW. In this case TG-DTA, according to NMR data, also highlighted the changes in the CW chemical structure compared with that of the litters, in particular the loss of waxes and the decreased thermostability of aromatic components. Moreover, a new concept of quality of the decomposing litter, based on the balance between the energy stored in the litter and the energy needed to release it obtained by thermal analysis, was recently introduced. Samples of the old forest litter had an initial energetic balance more favorable than those collected in the young stand. At the end of the period, the decrease in litter quality was greater in the young than in the old forest samples, due to the combined effect of the higher degradation of thermolabile substances and the accumulation of more thermostable components. Thermal analysis seems to have a good potential in litter decomposition studies, as it can link structural and energetic changes during the process.

Keywords: Thermal Analysis, Litter Quality, NMR, Cellulose, Lignin, Cell Wall

\section{Introduction}

In recent years several methods have been suggested to evaluate the chemical composition of litter and its change during the decomposition process. When environmental factors, such as temperature, redox potential and water availability are the same, the litter decay depends on its chemical composition, in particular the nutrients content and the ratio between labile and recalcitrant compounds. These characteristics, together with the physical structure of decomposing litter
(1) Department of Agricultural Sciences, Alma Mater Studiorum University of Bologna, v.le Fanin 40, I-40127 Bologna (Italy); (2) Department of Chemical and Geological Sciences, University of Modena and Reggio Emilia, v. G. Campi 183, 41125 Modena (Italy); (3) Faculty of Science and Technology, Free University of Bozen/Bolzano, p.za Università 5, I-39100 Bolzano (Italy)

\section{@ Paola Gioacchini (paola.gioacchini@unibo.it)}

Received: Mar 25, 2014 - Accepted: Oct 16, 2014

Citation: Gioacchini P, Montecchio D, Ferrari E, Ciavatta C, Masia A, George E, Tonon G, 2015. Litter quality changes during decomposition investigated by thermal analysis. iForest 8: 827-837 [online 2015-03-19] URL: http://www.sisef.it/iforest/contents/?id=ifor1297-007

Communicated by: Renzo Motta define the litter quality that is a quantitative measure of the litter biodegradability by soil microflora. As decomposition proceeds the more labile substances are generally consumed first and faster than the recalcitrant ones, such as lignin and waxes, that tend to accumulate in the remaining litter, which quality consequently decreases. However, evidences have been reported in broad-leaf species that also recalcitrant components such as lignin can undergo microbial degradation since the beginning of decomposition, and decreases in lignin content up to $60 \%$ of the initial amount can be measured in the first six months of decomposition (Jacob et al. 2010)

Many indexes of litter quality were suggested as predictors of decomposition rate (Aerts 1997, Berg \& McClaugherty 2008). The frequently used $\mathrm{C}$ to nitrogen $(\mathrm{N})$ ratio was suggested as an index of the early stage of decomposition (Vallejo 1981), while long-term litter decay prediction was made by using the $\mathrm{N}$ or lignin content and their ratio (Meentemeyer 1978, Aber \& Melillo 1982, Melillo et al. 1982, 1989), and the ratio between lignin and lignin + holocellulose (Moorhead \& Sinsabaugh 2006).

For most of these indexes, a crucial point is the measurement of the lignin content, for which several methods have been developed over the last years. Some of them are nondestructive spectroscopic methods that exploit the chemical properties of lignin to $a b-$ sorb radiation in discrete regions of the electromagnetic spectrum. They are based on different spectroscopic technologies, such as infrared and diffuse-reflectance Fourier transform (DRIFT) spectroscopy (Schultz et al. 1985), near infrared spectroscopy (NIRS) and nuclear magnetic resonance (NMR) spectroscopy (Haw et al. 1984, Kögel-Knabner 2002). The high resolution magic angle spinning (HR-MAS) NMR, applied to charaterize lignin and other litter components, along with the application of ${ }^{13} \mathrm{C}-{ }^{1} \mathrm{H}$ correlation spectroscopy 2D NMR spectroscopy, allows key resonances of litter components to be sufficiently resolved and assigned (Kelleher et al. 2006, Hedenström et al. 2009). Nevertheless, the choice of the appropriate solvent (Simpson et al. 2001, Francioso et al. 2007) and the lignin standard for instrument calibration is a critical point (Brinkmann et al. 2002).

Chemical methods have also been frequently used in litter decomposition studies to estimate lignin content (Hatfield \& Fukushima 2005), where mineral acids are used to solubilize and hydrolyze carbohydrates in the samples, leaving the lignin as a residue that can be gravimetrically measured. In this case, the main problem is the interference of ashes and the presence of recombination products or proteins associated to the cell 
walls (Hatfield \& Fukushima 2005, Montané et al. 2010). Another drawback of the chemical methods is that true lignin cannot be distinguished from partially humified products, leading to an overestimation of the lignin content (Couteaux et al. 1995). In addition, the gravimetric method requires the extraction of the cell wall $(\mathrm{CW})$ as pre-treatment to isolate cellulose and lignin, but the effects of the extraction on the structure of these components is partially unknown.

Recently, thermal analyses were applied to understand modifications in chemical structures taking place during litter decomposition (Anghern-Bettinazzi et al. 1988, Kristensen 1990, Beyer et al. 1998, Rovira \& Vallejo 2000, Rovira et al. 2008, Trofimov \& Emelyanenko 2000, Plante et al. 2009) These techniques are based on a slow and continuous heating of the sample coupled with a simultaneous measurement of its weight loss (thermogravimetry, TG), and its energy exchange. The latter is generally estimated by measuring the temperature change of the sample compared to a standard (differential thermal analysis, DTA) or by the release of energy in the form of heat (differential scanning calorimetry, DSC). The simultaneous measurement of weight loss and enthalpy change provides an insight into the mechanism underlying the energy change. The mass loss and the energy changes during heating are strictly related to the structural composition of the samples that can be directly analyzed without any pre-treatment.

Rovira et al. (2008) introduced an energetic approach to study changes of organic matter (OM) quality during litter decomposition by applying DSC. According to their results, the stability of any organic substrate attacked by microbes depends on the balance between the energetic input needed for its oxidation and the resulting net energetic output. The difference between the input needed and the energy released represents a net out put of energy available for the organism growth, as long as other factors are not limiting such as temperature, $\mathrm{O}_{2}$ and water availability.

In this study we evaluate the potential of thermal analysis technique in determining structural changes during litter decomposition of two broadleaf forests differing in their age. A short-term decomposition experiment was carried out to evaluate whether even small quality changes of litters were detectable with this technique. To this purpose, TG-DTA data were compared to the cellulose and lignin dynamics measured by chemical method that requires, as a first step, the extraction of CW. The thermal behavior of $\mathrm{CW}$ was therefore investigated. Moreover, the energetic approach introduced by Rovira et al. (2008) to study litter quality changes during litter decomposition process was applied.

\section{Material and methods}

\section{Site description and litter} decomposition study

The present study was carried out over a 9month period, from April to December 2003, in two adjacent woodlands characterized by a similar species composition, but with different ages. The older stand was a 280-year old hardwood forest, while the younger was a 30-year old plantation established on former agricultural land. In both forests, oak (Quercus robur), ash (Fraxinus angustifolia), poplar (Populus alba) and willow (Salix alba) were the dominant species. The area is located in the north-east Italy $\left(11^{\circ} 23^{\prime}\right.$ $\mathrm{N}, 44^{\circ} 49^{\prime} \mathrm{E}$ ). The climate is classified as temperate continental with a mean annual temperature of $13{ }^{\circ} \mathrm{C}$ and a mean annual rainfall of $698 \mathrm{~mm}$ (30 year average). Summer precipitations are less than $150 \mathrm{~mm}$.

Litter decomposition was studied using the litter-bag technique, nylon bags $(20 \times 20$ $\mathrm{cm}$ ) of $1 \mathrm{~mm}$ mesh size were used (Gallardo \& Merino 1993) to prevent major losses of small plant material, allowing an aerobic microbial activity and the entry of small soil fauna. Five grams of air-dried leaf litter were weighed and put in the litter-bags anchored to the forest floor with spikes at all 4 corners. Nine litter bags per site randomly distributed on the forest floor were used in the present study. At every sampling three litter bags were collected, carefully cleaned from extraneous plant and soil materials, dried overnight at $60{ }^{\circ} \mathrm{C}$, weighed, and ground before analysis. Sampling was carried out at time zero (beginning of the decomposition study), after 3 and after 9 months.

\section{Cell wall extraction}

The CW was extracted according to the method of Brinkmann et al. (2002). Two hundred $\mathrm{mg}$ of finely ground litter samples were suspended in $20 \mathrm{~mL}$ of washing buffer (100 mM K $\mathrm{K}_{2} \mathrm{HPO}_{4} / \mathrm{KH}_{2} \mathrm{PO}_{4}, \mathrm{pH} \quad 7.8,0.5 \%$ Triton $\mathrm{X}-100$ ), stirred overnight at room temperature and centrifuged at $5500 \times \mathrm{g}$ for $20 \mathrm{~min}$. The pellet was re-suspended in the washing buffer and the extraction was repeated twice (for $30 \mathrm{~min}$ ). The resulting pellet was washed four times $(30 \mathrm{~min}$ each time) in $\mathrm{MeOH}$. The $\mathrm{CW}$ thus obtained was dried at $80{ }^{\circ} \mathrm{C}$ for $12 \mathrm{~h}$ and weighed before being utilized for further analyses.

\section{Cellulose and lignin content}

Cellulose was determined using a $72 \%$ sulfuric acid digestion. Residual tissue from the digest was considered as lignin, and the mass lost during the digestion was considered as cellulose (Aber \& Martin 2002). Briefly, 25 $\mathrm{mg}$ of CW (W1 - three replicates per sample) were weighed into $15 \mathrm{~mL}$ screw cap plastic tubes, and $0.35 \mathrm{~mL}$ of $72 \% \mathrm{H}_{2} \mathrm{SO}_{4}$ was added. The powder was carefully mixed with
$\mathrm{H}_{2} \mathrm{SO}_{4}$ and primary hydrolysis occurred at 30 ${ }^{\circ} \mathrm{C}$ for $30 \mathrm{~min}$, then distilled water was added to reach a final volume of $10 \mathrm{~mL}$. After mixing, the samples were boiled for 4 hours to complete the hydrolysis. Samples were then cooled with tap water and the suspension was transferred into a $10 \mathrm{~mL}$ plastic syringe and filtered with a Millipore filtering system (HATF $45 \mu \mathrm{m}$ filter). After the first filtration, $3 \mathrm{~mL}$ of distilled water was added to the $15 \mathrm{~mL}$ plastic tube, shaken and filtered. The above procedure was repeated three times. The HATF filter was oven dried at 80 ${ }^{\circ} \mathrm{C}$, then transferred to a desiccator under $\mathrm{P}_{2} \mathrm{O}_{5}$ until constant weight was reached. Cellulose content was obtained by subtracting the final weight value from the sum of the initial CW sample and HATF filter. The residue was dried at $105{ }^{\circ} \mathrm{C}$ for two hours, cooled, and weighed (W2). The residue was ignited at $550{ }^{\circ} \mathrm{C}$ for two hours according to the Klason's method, cooled, and weighed to determine ash content (W3). Lignin content (\%) was calculated as $[(\mathrm{W} 2-\mathrm{W} 3) \cdot 100] / \mathrm{W} 1$ (Allen 1989).

\section{Elemental analysis}

Elemental analyses were carried out on both whole litter samples and extracted $\mathrm{CW}$. Carbon and $\mathrm{N}$ content were measured with an elemental analyser (CHNS-O mod. EA 1110 Thermo-Fisher) using acetanilide as a standard.

\section{Nuclear Magnetic Resonance (NMR) analysis}

High Resolution Magic Angle Spinning (HR-MAS) NMR spectra were recorded with a Bruker FT-NMR Avance 400 Spectrometer at $298 \mathrm{~K}$ using $8 \mathrm{kHz}$ spinning rate. Nominal frequencies were $400.13 \mathrm{MHz}$ for ${ }^{1} \mathrm{H}$ and $100.61 \mathrm{MHz}$ for ${ }^{13} \mathrm{C}$. An internal lock on the deuterium of DMSO- $d_{6}$ was used for all spectra. Each sample ( $\sim 30 \mathrm{mg})$ was dissolved in $100 \mu \mathrm{L}$ of DMSO- $d_{6}$ and introduced in a $90 \mu \mathrm{L}$ HR-MAS zirconium rotor (4 mm OD) and transferred into the MAS probe. The chemical shifts were referred to TMS. 1DNMR data were acquired using standard pulse sequence, the bipolar longitudinal eddy current delay pulse sequence (BPPLED - Wu et al. 1995, Johnson 1999) and the Carr-Purcell-Meiboom-Gill (CPMG) sequence, commonly known respectively as "zg", "ledbpgs2s" and "cpmg1d" in the standard Bruker library. For BPPLED sequence $1 \mathrm{k}$ scans were collected, implying a bipolar pulse pair ranging from 2 to $3 \mathrm{~ms}$, with a diffusion time of 100-200 ms, and a time domain point of $8 \mathrm{k}-16 \mathrm{k}$. The gradient length and diffusion time were varied in each sample in order to achieve $95 \%$ signal suppression at maximum gradient strength. In order to eliminate diffusion and $\mathrm{J}$ effects in the 1D-CPMG experiments, the ECHO evolution delay was set to $1 \mathrm{~ms}$, the number of 
loops (L1) ranged from 80 to $180,1 \mathrm{k}$ scans, $16 \mathrm{k}-32 \mathrm{k}$ time domain points and $2 \mathrm{sec}$ relaxation delay.

All the samples were investigated by applying different pulse sequences, in order to obtain 1D ${ }^{1} \mathrm{H}$ NMR spectra. Carr-Purcell-Meiboom-Gill (CPMG) sequence combined with a pre-saturation pulse for water suppression allowed the best results. Since integrated areas of the same spectral region may significantly vary according to the pulse sequence applied for acquisition, only integrated areas derived from CPMG for semi-quantitative discussion were used.

Additional information should be derived from carbon resonances. However, the weak sensitivity of ${ }^{13} \mathrm{C}$ nuclei and its long relaxation delays give poor signal-to-noise ratio, despite very long acquisition times that may exclude extremely high time-consuming 1D ${ }^{13} \mathrm{C} \mathrm{NMR}$, in favor of $2 \mathrm{D}{ }^{1} \mathrm{H}{ }^{13} \mathrm{C}$ correlated NMR experiments, which exploit the power of "inverse detection" and pulsed-field gradients.

2D homonuclear shift correlation $(\mathrm{H}, \mathrm{H}-$ COSY) spectra was obtained using the Bruker pulse sequence "cosygpqf" implying gradient pulses for selection with second flip angle being $90^{\circ}$.

The phase sensitive $2 \mathrm{D}{ }^{1} \mathrm{H},{ }^{13} \mathrm{C}$ HSQC was performed via the double INEPT transfer using Echo/Antiecho-TPPI gradient selection, and decoupling during acquisition was performed using TRIM pulses in INEPT transfer with multiplicity editing during the selection step (Willker et al. 1993).

\section{Thermal analysis}

Simultaneous thermogravimetric (TG) and differential thermal (DTA) analyses were performed on all samples to record continuous weight losses during sample heating and the corresponding energy changes as endothermic or exothermic reactions. The beginning and the end of mass loss for each reaction, was calculated by DTG (the first derivative of TG curve, which is the rate at which the mass of decomposing samples changes with respect to its changing tempe- rature). DTG curve allows converting the TG trace into well defined peaks.

Two high purity standards indium and aluminum (both $99.99 \%$ ) were used to calibrate TG-DTA for both temperature $\left({ }^{\circ} \mathrm{C}\right)$ and enthalpy ( $\mathrm{J} \mathrm{g}^{-1}$ - Hatakeyama \& Zhenhai 1998). Litter and their $\mathrm{CW}$ samples (about $5 \mathrm{mg}$ ) were analyzed by the TG-DTA92B instrument managed by a SETSOFT2000 software (SETARAM, France). A heating rate of 10 ${ }^{\circ} \mathrm{C} \min ^{-1}$ from $30{ }^{\circ} \mathrm{C}$ to $800{ }^{\circ} \mathrm{C}$ under dynamic air flow $\left(8 \mathrm{~L} \mathrm{~h}^{-1}\right)$ was used; details about these procedures have been previously described by Montecchio et al. (2006). The total OM loss was measured as the weight loss between $105^{\circ} \mathrm{C}$ and $600{ }^{\circ} \mathrm{C}$. No weight losses were observed at temperatures above $600{ }^{\circ} \mathrm{C}$. The final remaining weight was considered as ash. Each sample was analyzed three times.

Changes in litter quality during decomposition were evaluated applying the energetic balance concept reported by Rovira et al. (2008). Both energy outputs and inputs were calculated for each sample at the beginning and at the end of the decomposition period. The energy output is the energy stored in the litter sample, expressed as $\mathrm{J} \mathrm{mg}^{-1}$ of OM calculated by integrating the area under the DTA curve. The energy input is the energy needed to thermo-decompose the litter, and was estimated by calculating the $\mathrm{T}_{50}$ for DTA that is the value of temperature $\left({ }^{\circ} \mathrm{C}\right)$ at which the sample releases half of its total stored energy. This parameter was used as an indicator of the cost of releasing the stored energy, therefore changes in the balance between the energy input and output were used to evaluate changes in litter quality during decomposition.

\section{Statistical analysis}

Data were analyzed by means of ANOVA using the STATGRAPHICS ${ }^{\circledR}$ software package (Statpoint Technologies, USA) using the stand age and the decomposition time as independent variables, and their interaction was also evaluated at $\alpha=0.05$.

ANCOVA was used to compare slopes and intercepts of the linear regression between EXO1 mass loss (TG-DTA data) and cellulose content, and between EXO2 mass loss (TG-DTA data) and lignin content.

\section{Results}

\section{$C$ and $N$ content of degrading litters}

The litter mass (\% of the original biomass) at the end of the study did not differ between the two stands analyzed, though a significant loss was observed just after 3 months in the young forest (Tab. 1). The initial C content of the two litters was about $46 \%$ (Tab. 1). Differences between the two stands showed that there was a quicker decrease in the young forest, where about $23 \%$ of the initial $\mathrm{C}$ content was lost after 9 months, while in the old forest a decrease of about $17 \%$ occurred over the same period (Tab. 1). On the contrary, $\mathrm{N}$ increased over the studied period in both forest litters, from 2.3 to $2.6 \%$ in the young and from 1.8 up to $2.1 \%$ in the old stand (Tab. 1). The initial cellulose content was greater in the young stand than in the old forest litter, but it was lower in the young forest litter at the intermediate sampling, due to a faster degradation that occurred during the first 3 months (Fig. 1a). At the end of the study, about $18 \%$ of the initial cellulose content was degraded in the young litter and $7 \%$ in the old forest litter. However, no significant differences in the final cellulose content between the two litters were detected (Fig. 1a). The lignin content was significantly lower in the young litter than in the old forest litter throughout the study period, and at the end of the experiment a decrease of about $8 \%$ of the initial content was observed in the young litter and $6 \%$ in the old forest litter (Fig. 1b).

\section{$C$ and $N$ of cell walls}

Throughout the experiment, the $\mathrm{C}$ content of the $\mathrm{CW}$ was about $6 \%$ less than the $\mathrm{C}$ content of the young forest litter and 3\% less than the $\mathrm{C}$ content of the old forest litter (Tab. 1). The $\mathrm{N}$ content of young forest litter was negatively affected by the extraction

Tab. 1 - Mass remaining (\% of the original) $\mathrm{C}$ and $\mathrm{N}$ content of the litter and relative $\mathrm{CW}$ from young and old forest stands during the de composition period. Numbers within a column denoted by different capital letters are significantly different after Tukey's test $(\mathrm{P}<0.05)$; numbers within each parameter followed by different lowercase letters denote statistically significant differences between Litter and CW values according to the Tukey test $(\mathrm{P}<0.05)$; numbers within each parameter and type of plant tissue followed by a asterisk denote statistically significant differences between the two forests after Tukey's test $(\mathrm{P}<0.05)$. Values in brackets are standard errors $(\mathrm{n}=3)$.

\begin{tabular}{|c|c|c|c|c|c|c|c|c|c|c|}
\hline \multirow{3}{*}{ Months } & \multicolumn{5}{|c|}{ Young Forest } & \multicolumn{5}{|c|}{ Old Forest } \\
\hline & \multirow{2}{*}{$\begin{array}{c}\text { Mass } \\
\text { remaining }\end{array}$} & \multicolumn{2}{|c|}{$\mathrm{C}(\%)$} & \multicolumn{2}{|c|}{$\mathbf{N}(\%)$} & \multirow{2}{*}{$\begin{array}{l}\text { Mass } \\
\text { remaining }\end{array}$} & \multicolumn{2}{|c|}{$\mathrm{C}(\%)$} & \multicolumn{2}{|c|}{ N (\%) } \\
\hline & & Litter & $\mathrm{CW}$ & Litter & $\mathbf{C W}$ & & Litter & CW & Litter & $\mathbf{C W}$ \\
\hline 0 & - & $\begin{array}{l}46.4 \text { a A } \\
(0.14)\end{array}$ & $\begin{array}{l}39.2 \mathrm{~b} \mathrm{~A} \\
(0.70)\end{array}$ & $\begin{array}{l}2.34 * \mathrm{a} \\
(0.12)\end{array}$ & $\begin{array}{l}1.89 \mathrm{~b} \\
(0.01)\end{array}$ & - & $\begin{array}{c}46.1 \mathrm{a} \mathrm{A} \\
(0.50)\end{array}$ & $\begin{array}{l}42.8 \mathrm{~b} \text { A } \\
(0.38)\end{array}$ & $\begin{array}{l}1.76 * \mathrm{~A} \\
(0.03)\end{array}$ & $\begin{array}{c}1.76 \\
(0.11) \\
\end{array}$ \\
\hline 3 & $\begin{array}{l}74.2 * \mathrm{~A} \\
(2.03)\end{array}$ & $\begin{array}{l}40.5 \text { a B } \\
(0.79)\end{array}$ & $\begin{array}{l}34.4 * b \text { B } \\
(1.75)\end{array}$ & $\begin{array}{l}2.50 * a \\
(0.07)\end{array}$ & $\begin{array}{l}2.10 \mathrm{~b} \\
(0.06)\end{array}$ & $\begin{array}{l}89.04 * \mathrm{~A} \\
(1.09)\end{array}$ & $\begin{array}{l}42.6 \text { a B } \\
(1.16)\end{array}$ & $\begin{array}{l}39.2 * b \mathrm{~B} \\
(1.67)\end{array}$ & $\begin{array}{l}2.20 * \mathrm{~B} \\
(0.04)\end{array}$ & $\begin{array}{c}2.09 \\
(0.05) \\
\end{array}$ \\
\hline 9 & $\begin{array}{l}65.5 * \mathrm{~B} \\
(4.49)\end{array}$ & $\begin{array}{l}35.8 * \mathrm{a} \mathrm{C} \\
(1.87)\end{array}$ & $\begin{array}{l}29.9 * \mathrm{~b} \mathrm{C} \\
(2.61)\end{array}$ & $\begin{array}{l}2.59 * \mathrm{a} \\
(0.10)\end{array}$ & $\begin{array}{l}2.20 \mathrm{~b} \\
(0.04)\end{array}$ & $\begin{array}{l}72.32 * \mathrm{~B} \\
(5.86)\end{array}$ & $\begin{array}{l}38.3 * a \mathrm{C} \\
(0.77)\end{array}$ & $\begin{array}{l}35.2 * \mathrm{~b} \mathrm{C} \\
(0.29)\end{array}$ & $\begin{array}{l}2.10 * \mathrm{~B} \\
(0.04)\end{array}$ & $\begin{array}{c}2.11 \\
(0.04)\end{array}$ \\
\hline
\end{tabular}


Fig. 1 - Changes of cellulose and lignin content in the leaf litter of young and old forest stands during the decomposition period. Different capital letters indicate significant differences among sampling times, asterisks denote significant differences between sites $(\mathrm{P} \leq 0.05, \mathrm{NS}=$ not significant).
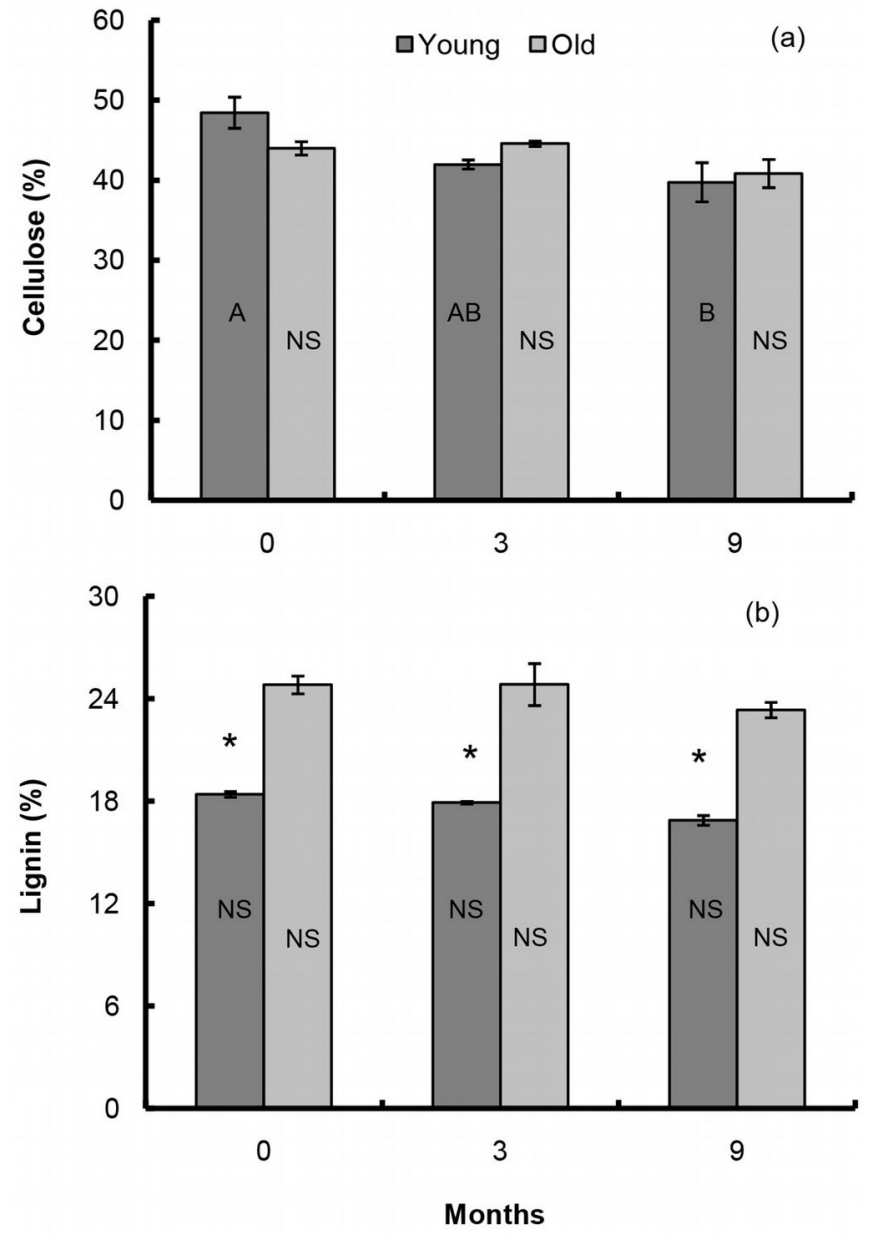

procedure, which led on an average reduction of $0.4 \%$ of $\mathrm{N}$ content (Tab. 1). In the old forest no difference in $\mathrm{N}$ content was observed between litter and CW (Tab. 1).

NMR spectroscopy of degrading litters

Fig. 2 and Fig. 3 show the comparison of 1D ${ }^{1} \mathrm{H}$ NMR spectra of young forest and old forest litters at time zero and after 9 months. For all the samples, typical spectral regions corresponding to the main components can be assigned and they are represented by: (1) lignins, amide group in peptides, aromatics, conjugated $-\mathrm{CH}=\mathrm{CH}-$, aromatic amino acids (9-6 ppm); (2) lignin, carbohydrates, $\alpha / \beta$ protons in peptides, ethers (6-2.5 ppm); (3) side chain protons in amino acids (2.3-2.0 ppm); (4) $-\mathrm{CH}_{2}$ - chains of lipids, waxes and cuticles (2-0.8 ppm); and (5) terminal $\mathrm{CH}_{3}$ groups 0.8-0 ppm (Kelleher et al. 2006, Ferrari et al. 2011). Proton spectra highlights some differences in the nature of the two forest litters (Fig. 2 and Fig. 3), especially the presence of more distinct and sharp resonances in the young forest as compared with the old one. The resonances in the aliphatic region may be attributed to smaller structures, to a lower degree of polymerization of aliphatic chains of waxes and lipids, as well as to branched chains as supported by the high content of terminal $\mathrm{CH}_{3}$.

The evaluation of phase sensitive ${ }^{1} \mathrm{H},{ }^{13} \mathrm{C}$ HSQC experiments of old forest and young forest litters (Fig. 4) showed similar correlation peaks. The presence of carbohydrates (Fig. 4) was underestimated in ${ }^{1} \mathrm{H}$ spectra due to water suppression, especially in the region 4-3.2 ppm, so it is better observed by hetero-correlated spectroscopy. Some interesting differences appeared in the three regions emphasized by ellipses (Fig. 4): young forest litter wass characterized by some typical cross peaks (ellipsis 1 - Fig. 4) corresponding to sharp and definite proton signals in $1 \mathrm{D}{ }^{1} \mathrm{H}$ spectrum, which may be ascribed to cyclic hydrocarbon structures, such as steroids and triterpenoids, as reported by Kelleher et al. (2006). Furthermore, old forest litter was richer in insaturation, as shown by the correlations of $\mathrm{C}-\mathrm{H}$ of double bonds on aliphatic chain and conjugated aromatic structures (ellipsis 3). Finally, the two forest litters differed also in the aliphatic region (ellipsis 2) which is due to $\mathrm{C}-\mathrm{H}$ bonds from various aliphatic structures including fatty acids and amino acids.

After 9 months of degradation the differences observed between the two litters at time zero were dramatically reduced. For both forest litters, the decomposition is reflected in the broadening of resonance peaks, which is indicative of biopolymer functionalization and/or oxidation, resulting in a heterogeneous mixture of compounds (Wershaw et al. 1996). Proton signal corresponding to double bonds strongly decreased, likely due to oxidation processes during decomposition, while anomeric proton signal $(4.9 \mathrm{ppm})$ remained unaffected, suggesting that the degrading period could be too short to register considerable effects on carbohydrate moieties. Moreover, it is likely that the carbohydrates were mainly in a form scarcely bioavailable, such as crystalline cellulose, hemicelluloses and part of a heterogeneous matrix provided by lignin, in which polysaccharides become embedded and cross-linked to form a recalcitrant polymer network (Kelleher et al. 2006).

\section{NMR spectroscopy of cell walls}

The CW extraction considerably decreased the content of aliphatic structures (3-5 regions), especially in cuticles and waxes, while the aromatic signals, related to lignins, resulted more evident due to an increased signal-to-noise ratio. When compared to litters, CW NMR spectra (Fig. 2, Fig. 3) showed sharp peaks, particularly in the aliphatic region, a clue of a diminished degree of polymerization, with a corresponding increase in the terminal $\mathrm{CH}_{3}$ signal $(0.65 \mathrm{ppm})$. The spectral pattern of aromatic regions points out a well resolved spin system with the typical ${ }^{3} \mathrm{~J}_{\mathrm{HH}(\text { ortho) }}$ coupling constant of $\sim 8$ $\mathrm{Hz}$, which was found only in $\mathrm{CW}$ extracts and may be attributed to coumaryl and guaiacyl aromatic structures of the lignin. Another diagnostic peak for the presence of lignin was represented by the singlet at $\sim 4$ ppm, due to the methoxyl substituents on the aromatic rings.

Phase sensitive ${ }^{1} \mathrm{H},{ }^{13} \mathrm{C}$ HSQC experiments of $\mathrm{CW}$ support the results from $1 \mathrm{D}{ }^{1} \mathrm{H}$ spectra, showing (Fig. 4) new correlations in the aromatic region, due to guaiacyl and coumaryl scaffolds (Fig. 4). However, the main differences from litters were observed in the aliphatic region, where aliphatic correlations corresponding to sharp resonances (ellipses 1 and 2 - Fig. 4) almost disappear. The presence of carbohydrates resulted almost unaffected by CW extraction, as shown by the persistence of cross-peaks corresponding to sugar moieties (Fig. 4 - squared box).

\section{Thermal analysis of degrading litters}

The differential thermal analysis (DTA) of litter samples from both forests during the whole decomposition period was characterized by the presence of a small endothermic peak related to the sample dehydration and three exothermic peaks (Fig. 5). The endothermic peak accounted for about $4 \%$ in 


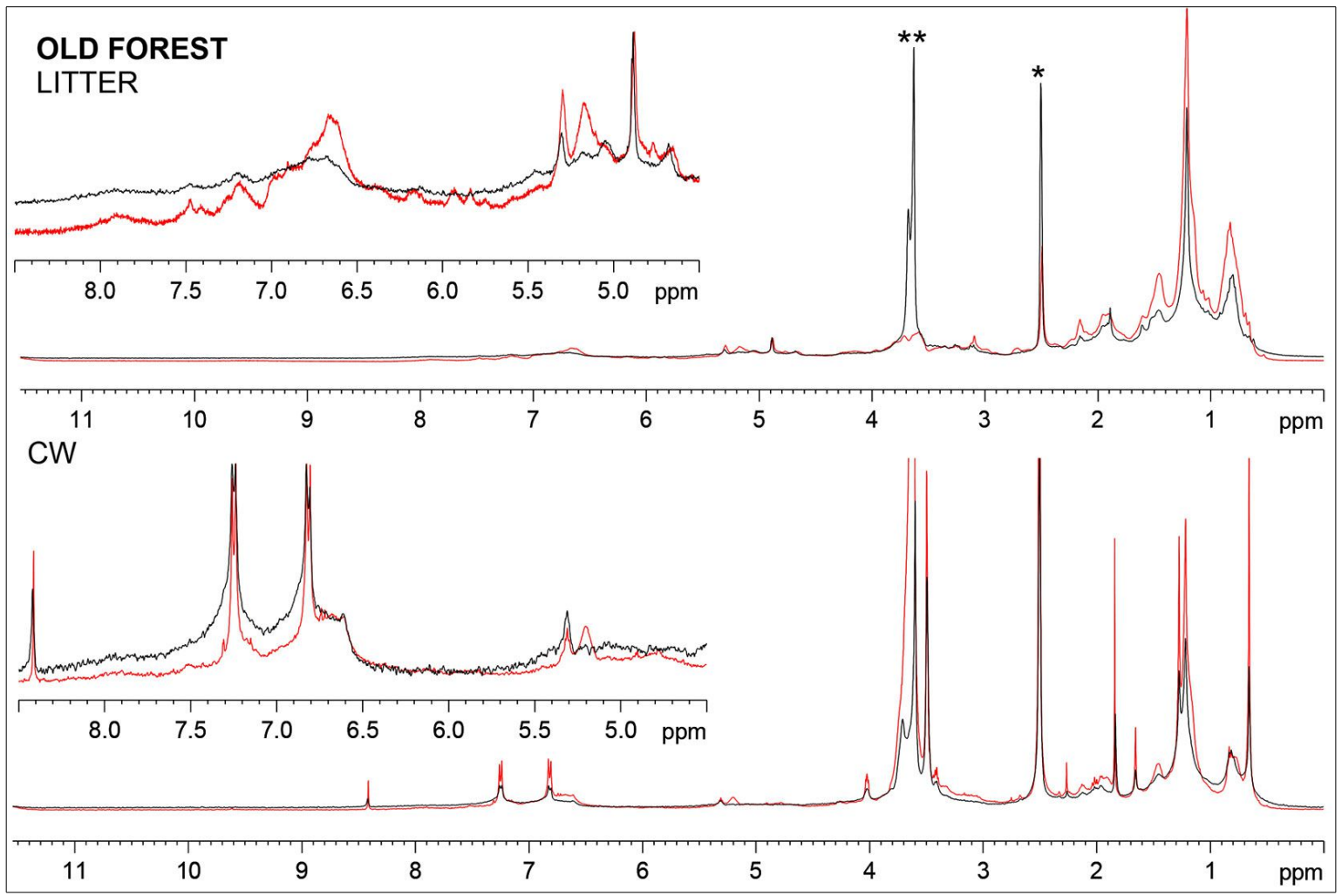

Fig. 2 - ${ }^{1} \mathrm{H}$ HRMAS NMR spectra of the litter from the young forest stand and their $\mathrm{CW}$ at the beginning (red line) and at the end (black line) of the decomposition period. $(*)$ : residual DMSO; $(* *)$ : residual HOD.

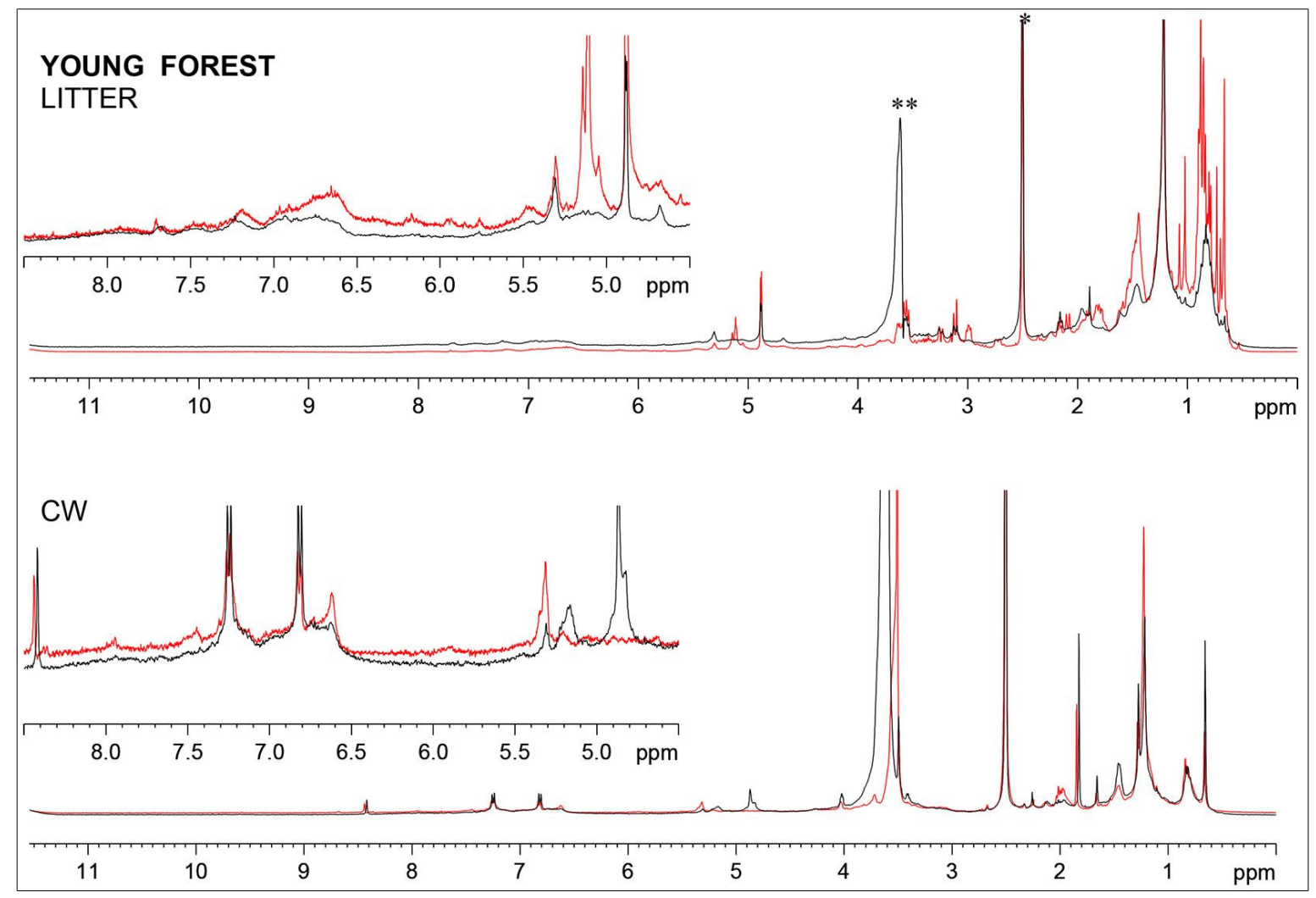

Fig. 3 - ${ }^{1} \mathrm{H}$ HRMAS NMR spectra of the litter from the old forest stand and their CW at the beginning (red line) and at the end (black line) of the decomposition period. $(*)$ : residual DMSO; $(* *)$ : residual HOD. 
Fig. 4 - Phase sensitive ${ }^{1} \mathrm{H},{ }^{13} \mathrm{C}$ HSQC spectra of young forest litter and its CW (red) and old forest litter and its CW (green) at the beginning of decomposition. Arrow indicates methoxyl groups of lignins, circles emphasize the main differences between the two forest stands. Squared box highlights main carbohydrates correlations.
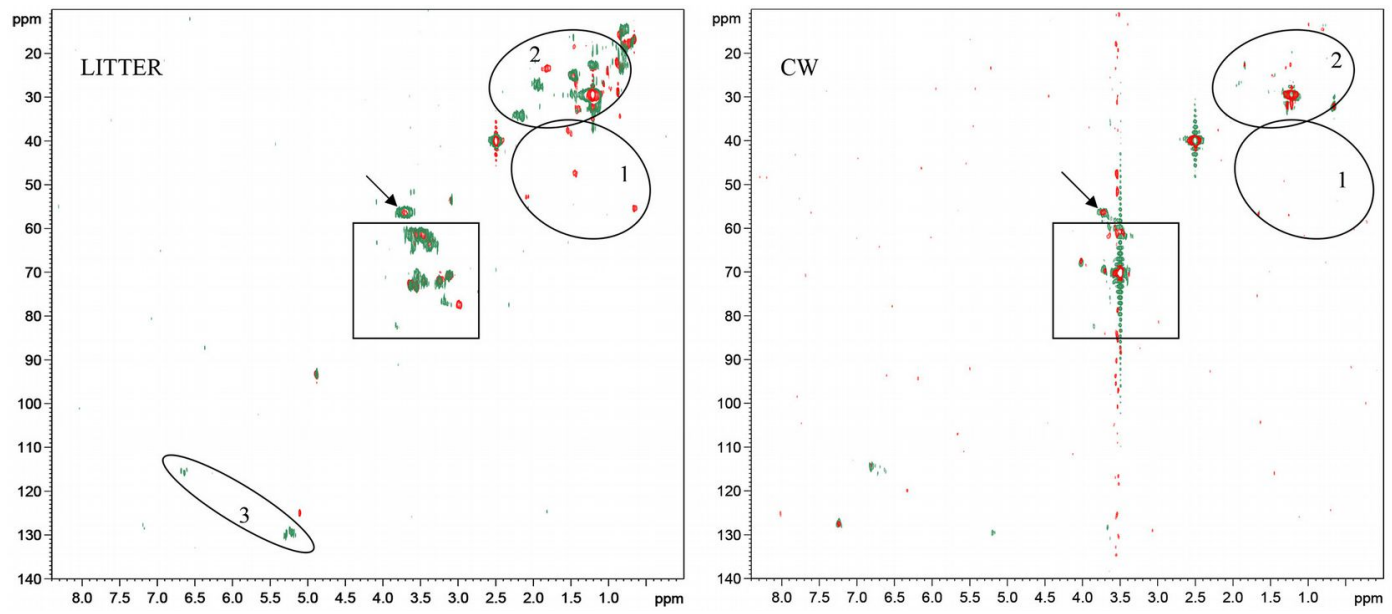

all litter samples. The first exothermic peak (EXO1) was in both forest litters approximately at $340{ }^{\circ} \mathrm{C}$. Such reaction is mainly due to the break of labile compounds such as aliphatic and/or alicyclic structures, especially polysaccharides and proteins. Therefore, in the case of plants debris, water soluble compounds, hemicellulose and cellulose are all included in this exothermic reaction (Reh et al. 1990, Kosheleva \& Trofimov 2008). The second exothermic peak (EXO2) was at around $465{ }^{\circ} \mathrm{C}$ in the young litter and $435{ }^{\circ} \mathrm{C}$ in the old forest litter, mainly due to the oxidation of more thermostable compounds such as aromatic rings. Lignin was assumed to break up in this exothermic reaction (Flaig et al. 1975, Rovira \& Vallejo 2000). The cyclic hydrocarbon structures revealed by NMR data in the young forest litter could be possibly related to the higher temperature of EXO2. The third peak
(EXO3) was characterized by a similar temperature in the two litters (about $515^{\circ} \mathrm{C}$ ); this reaction is due to the most thermally resistant organic components that could be related to the presence of hydrocarbons, esters, fatty acids and aromatic and cyclic compounds (Bianchi 1995).

Based on TG data, the OM content of litters at the beginning of the experiment was on average $79.2 \%$ in the young litter and $80.7 \%$ in the old forest litter. After 9 months of decomposition, the OM content decreased from the initial amount by $24 \%$ and $14 \%$ for the young and the old forest litters, respectively.

At the beginning of the experiment, EXO1 accounted for about $58 \%$ of litter biomass in both litters (Fig. 6a). During the decomposition period, EXO1 in the young forest litter progressively decreased by about $30 \%$ of the initial content and at the end of the experi-

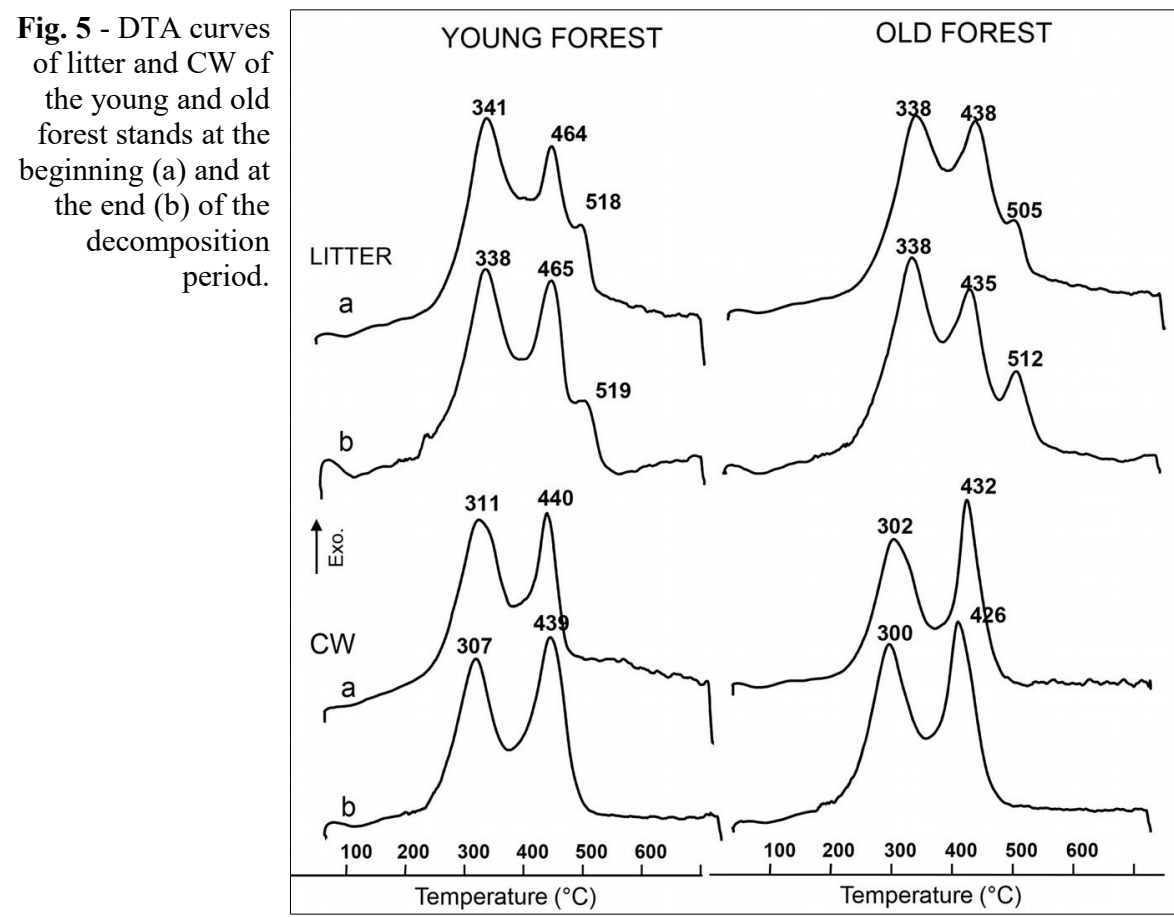

ment it represented around $41 \%$ of the litter biomass. A smaller decrease of EXO1 (about $20 \%$ ) was measured in the old forest, where it accounted for $46 \%$ of litter biomass at the end (Fig. 6a). Similarly, EXO2 decreased during the decomposition process. The initial value was $18 \%$ and $21 \%$ in the young and the old forest litter, respectively, but after 9 months of decomposition EXO2 decreased to $15 \%$ in the young and $17 \%$ in the old forest litter (Fig. 6b). However, except of the EXO2 values at the beginning of the experiment, no statistically significant differences were found between young and old forest litter for EXO1 and EXO2 peaks throughout the experiment.

The third most-recalcitrant peak (EXO3) was the smallest in terms of mass loss, comprising about 3\% in the young and 3.6\% in the old forest litter. Unlike EXO1 and EXO2, EXO3 constantly increased during decomposition until the end of the experiment, accounting for $4.2 \%$ in the young forest litter, with an increase by $40 \%$ of the initial amount. In the old stand litter, a higher increase of $58 \%$ of the initial EXO3 content was observed, and the final value accounted for $5.7 \%$ of residual litter biomass (Fig. $6 \mathrm{c}$ ).

\section{Thermal analysis of cell walls}

The extraction procedure modified the thermal behavior of the $\mathrm{CW}$ as compared with that of the untreated litters (Fig. 5). For both forests, CW DTA curves showed a first endothermic peak of about $4 \%$ due to the humidity content and only two exothermic peaks (EXO1 and EXO2), while the third most-recalcitrant peak at $515^{\circ} \mathrm{C}$, present in both litters, was absent from the DTA curves of $\mathrm{CW}$. Moreover, EXO1 and EXO2 peaks shifted towards lower temperature in comparison to the whole litters. EXO1 Tmax decreased by about $40{ }^{\circ} \mathrm{C}$ and was around 300 ${ }^{\circ} \mathrm{C}$ in the $\mathrm{CW}$ of both litters, whereas the Tmax of the EXO2 peak in the young forest $\mathrm{CW}$ shifted to a larger extent (about 25-30 ${ }^{\circ} \mathrm{C}$ ) than in the old forest (about $10^{\circ} \mathrm{C}$ - Fig. $5)$. 
The OM content of the CW was lower than that of the litters, with a decrease of $6.2 \%$ and $5.7 \%$ in the young and old forest, respectively. At the end of the study a decrease in $\mathrm{OM}$ of $25 \%$ of the initial content in the young forest and $18 \%$ in the old one was observed.

The dynamics of the two exothermic reactions in the $\mathrm{CW}$ is shown in Fig. 7a and Fig. $7 \mathrm{~b}$. The decrease of EXO1 related to carbohydrates in the $\mathrm{CW}$ (cellulose and hemicellulose) was similar to that observed in the litters. In the $\mathrm{CW}$ of the young forest samples such decrease was faster than in the $\mathrm{CW}$ from the old forest samples. A difference of $30 \%$ as compared with the initial amount was detected in the young forest $\mathrm{CW}$, while such difference was $17 \%$ in the old forest $\mathrm{CW}$. As previously observed for the litters, $\mathrm{EXO} 2$ in the $\mathrm{CW}$ of the old forest samples decreased more consistently than that of young forest samples: at the end of the study $19 \%$ of the initial amount was lost in the old forest $\mathrm{CW}$ and $14 \%$ in the young forest $\mathrm{CW}$.

\section{Relationship between $O M$ and $C$} content

Fig. 8 displays the relationship between the OM content measured by TG and the organic $\mathrm{C}$ content measured by elemental analysis. A good correlation $\left(\mathrm{R}^{2}=0.8564\right)$ was observed and the conversion factor obtained (1.7111) was very close to Van Bemmelen's factor (1.724) commonly used to derive the OM content from the organic $\mathrm{C}$ content (Jackson 1985).

\section{Comparison between chemical method and TG-DTA in estimating lignin and cellulose content}

As mentioned earlier, the oxidative degradation of cellulose takes place in EXO1 and that of lignin in EXO2, but in the complex structure of intact litters many others substances are lost together with these litter constituents. The presence of hemicelluloses and cellulose in the first peak, and tannins and polyphenolics other than lignin in the second peak, may lead to an overestimation of both litter components. As an effect of the extraction procedure, the $\mathrm{CW}$ has a structure simpler than that of the litter, since at least some of the substances interfering with the thermal measurement of cellulose and lignin have been eliminated. Therefore, TG-DTA applied to $\mathrm{CW}$ should be more accurate in the estimate of the cellulose and lignin content through EXO1 and EXO2 mass loss.

Taking into account the previous assumption and considering the litter, the estimates of cellulose and lignin content obtained with the chemical method and those obtained as mass loss of EXO1 and EXO2 showed a weak correlation for both forest litters (Fig. 9 ). On the contrary, when the thermal analysis was applied to the extracted $\mathrm{CW}$, the cor-

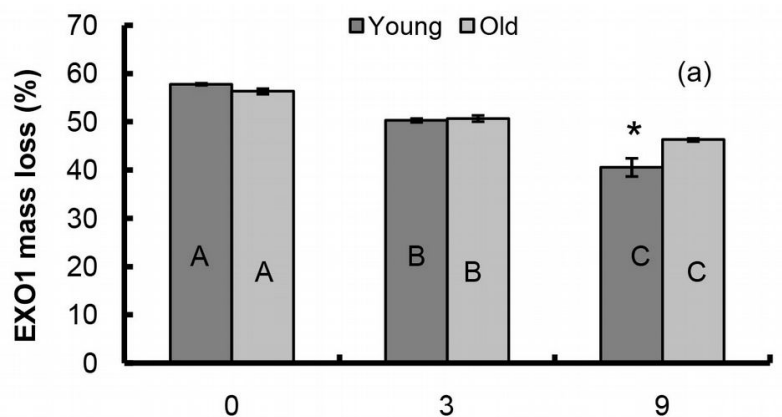

Fig. 6 - EXO1, EXO2 and EXO3 mass loss of young and old forest litters during the decomposition period. Different capital letters indicate significant differences among sampling times, asterisks denote significant differences between sites $(\mathrm{P} \leq$ $0.05)$.
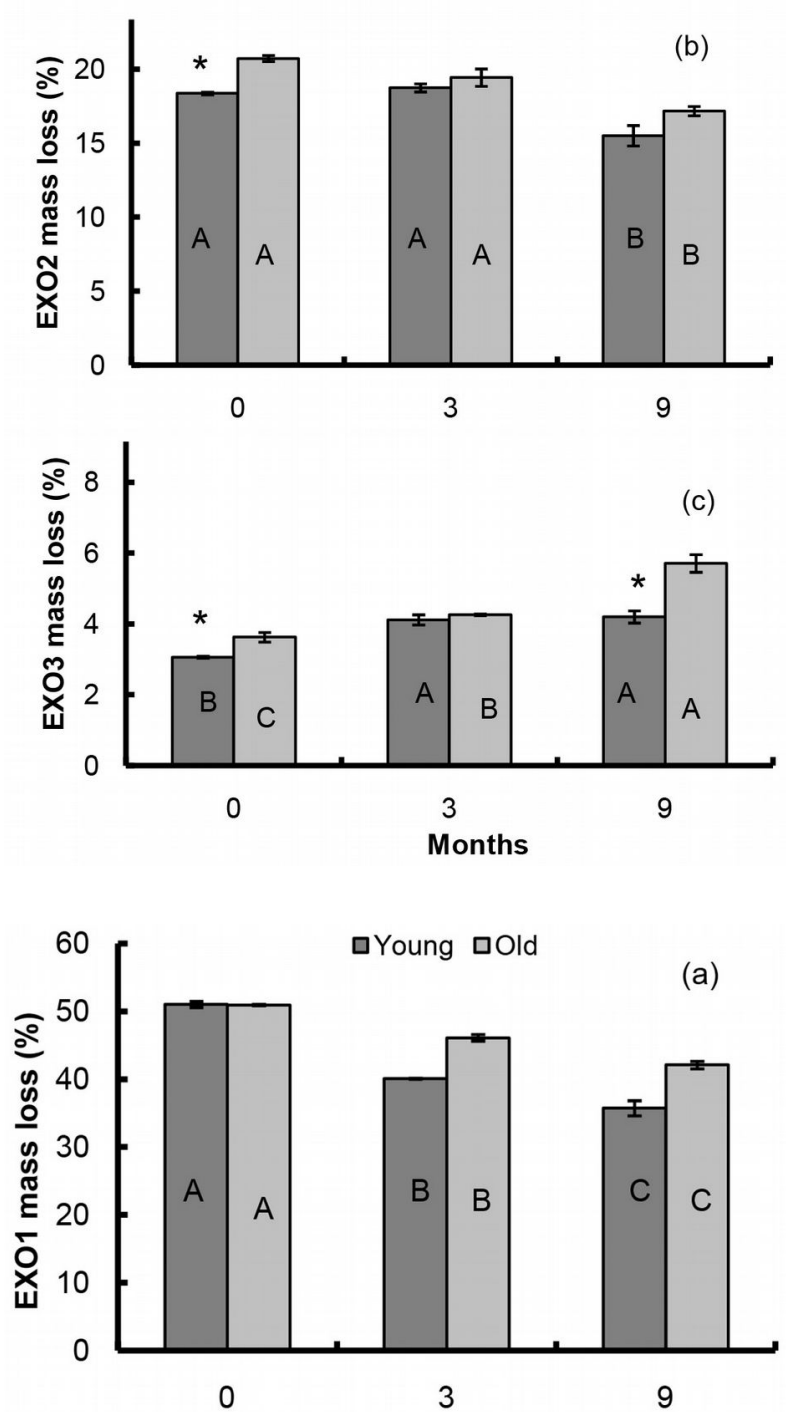

Fig. 7 - EXO1 and EXO2 mass loss of $\mathrm{CW}$ extracted from young and old forest litters during the decomposition period. Different capital letters indicate significant differences among sampling times, asterisks denote significant differences between sites $(\mathrm{P} \leq 0.05)$.

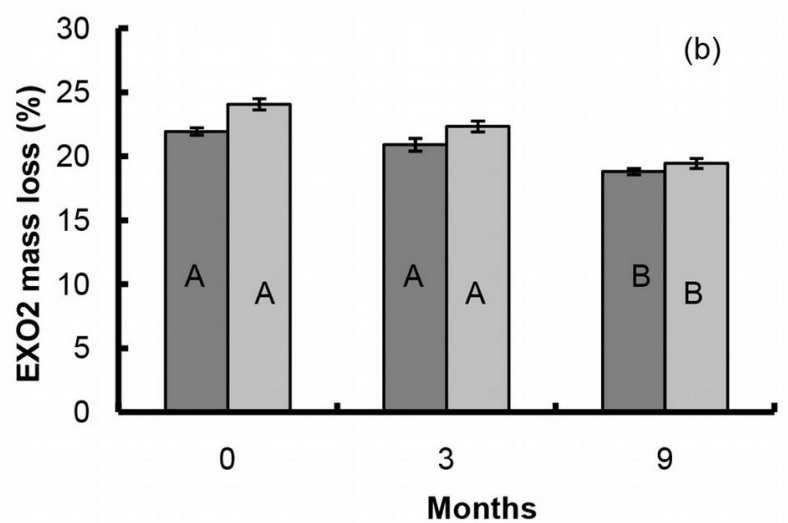




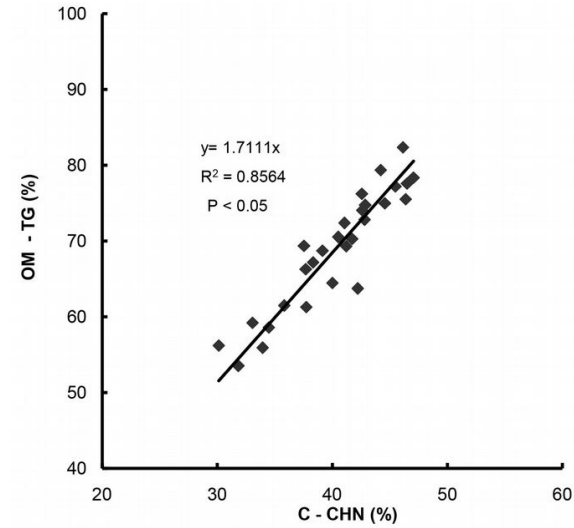

Fig. 8 - Relationship between OM content measured by thermal analysis (TG) and C content measured by elemental analysis $(\mathrm{CHN})$ in litter and $\mathrm{CW}$ of young and old forest stands.
Tab. 2 - Comparison of intercept and slope of the linear regression between EXO1 and cellulose content and between EXO2 and lignin content. Different lowercase letters indicate statistically significant differences between sites according to the ANCOVA test $(\mathrm{P}<0.05)$; different capital letters indicate statistically significant differences between tissues according to the ANCOVA test $(\mathrm{P}<0.05)$.

\begin{tabular}{llcccc}
\hline \multirow{2}{*}{ Parameter } & \multirow{2}{*}{ Tissue } & \multicolumn{2}{c}{$\begin{array}{c}\text { Cellulose vs. EXO1 } \\
\text { mass loss }\end{array}$} & \multicolumn{2}{c}{$\begin{array}{c}\text { Lignin vs. EXO2 } \\
\text { mass loss }\end{array}$} \\
\cline { 3 - 6 } & & Old Forest & Young Forest & Old Forest & Young Forest \\
\cline { 2 - 6 } Intercept & $\mathrm{CW}$ & $3.59 \mathrm{a} \mathrm{B}$ & $-1.33 \mathrm{~b} \mathrm{~B}$ & $-0.30 \mathrm{~b} \mathrm{~A}$ & $5.33 \mathrm{a} \mathrm{A}$ \\
& $\mathrm{Litter}$ & $8.39 \mathrm{a} \mathrm{A}$ & $3.93 \mathrm{a} \mathrm{A}$ & $-0.23 \mathrm{a} \mathrm{A}$ & $-11.15 \mathrm{~b} \mathrm{~A}$ \\
\hline Slope & $\mathrm{CW}$ & $0.88 \mathrm{a} \mathrm{A}$ & $0.84 \mathrm{a} \mathrm{A}$ & $0.80 \mathrm{a} \mathrm{A}$ & $0.73 \mathrm{a} \mathrm{A}$ \\
& Litter & $0.99 \mathrm{a} \mathrm{A}$ & $1.05 \mathrm{a} \mathrm{A}$ & $0.79 \mathrm{a} \mathrm{A}$ & $1.62 \mathrm{a} \mathrm{A}$ \\
\hline
\end{tabular}

relation between the content of cellulose and content when applied to the litter, and underlignin obtained by the two methods signifi- estimated it when applied to the CW (Fig. 9, cantly increased for both forests (Fig. 9). In Tab. 2). Whatever the tissue (CW or litter), comparison to the chemical method, the thermal analysis underestimated also the thermal analysis overestimated the cellulose lignin content when compared to chemical

\section{Young forest}
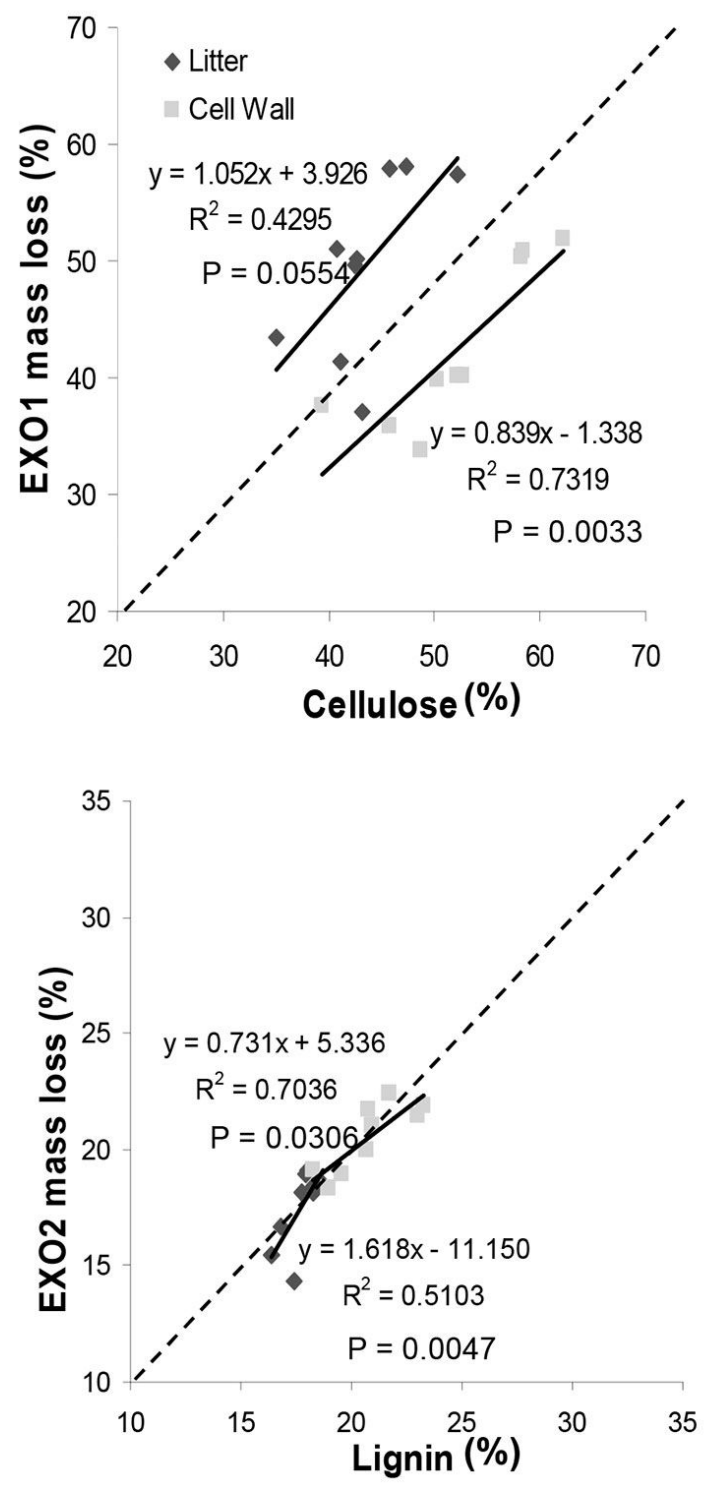

Old forest
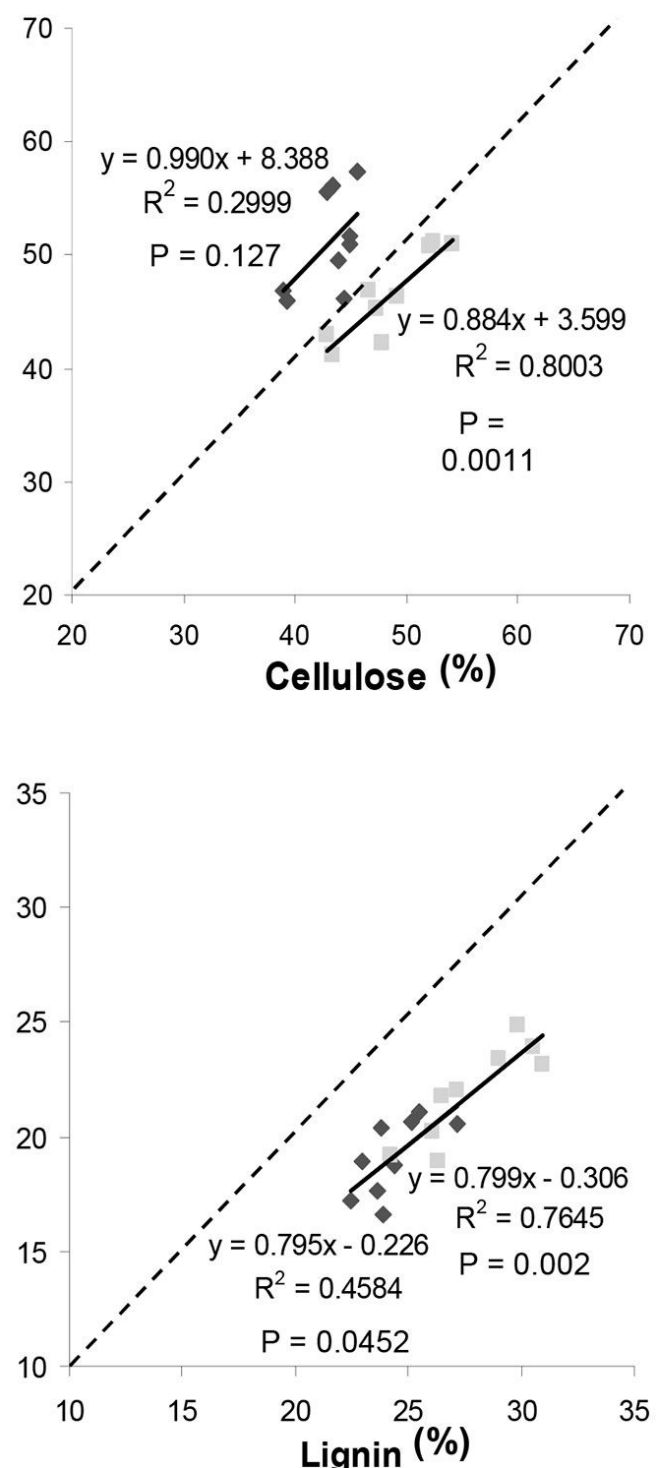

Fig. 9 - Relationship between cellulose and lignin content measured by thermal analysis (mass loss related to EXO1 and EXO2) and wet chemical method for young and old forest litters and their $\mathrm{CW}$. 
Fig. 10 - Quality change of litters of young (circles) and old (diamonds) stands during the decomposition period.

$\mathrm{T}_{50}$ for DTA has been taken as an indicator of the energy needed to release the energy stored in litter. Filled symbols: initial decomposition stage. Empty symbols: final decomposition stage.

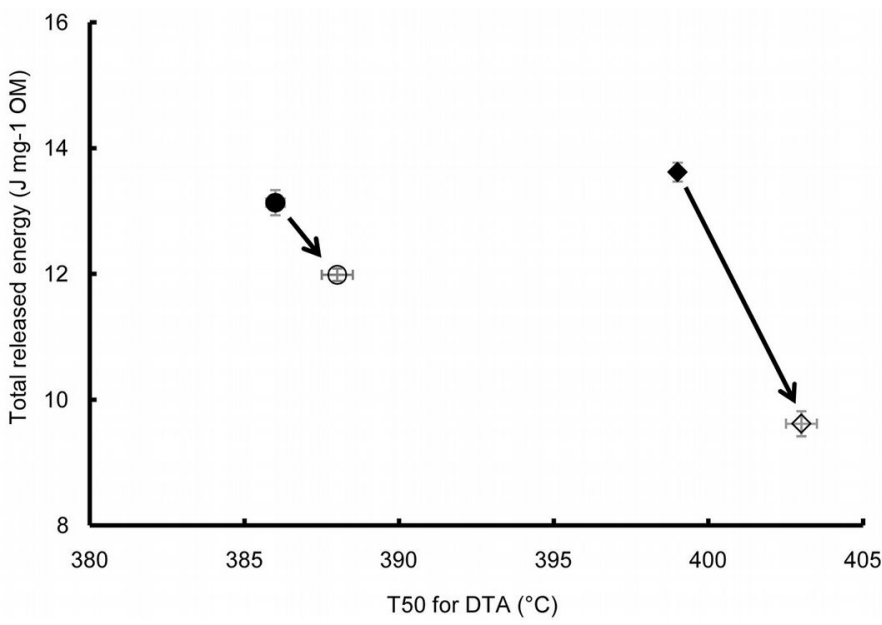

method, especially for young forest tissues (Fig. 9, Tab. 2).

When the regression lines between EXO1 mass loss and cellulose content were compared by ANCOVA, no difference in slope values was found between stands (young vs old) and between tissues (litter vs. CW). By contrast, the intercept values were significantly higher in litter than in $\mathrm{CW}$ in both young and old forest stands, and only for the CW the intercept value was higher in old than in young forest litters (Tab. 2). Moreover, the slope of the regression lines between EXO2 mass loss and lignin content was unaffected by stand age and tissue type, while the values of the intercept were higher in young forest in case of $\mathrm{CW}$ tissue and in old forest in case of litter (Tab. 2).

\section{Quality litters changes during decomposition}

At time zero, the two litters were characterized by a similar total energy content, but the energetic cost to recover such stored energy, as measured by the T50 for DTA, was higher in the young than the old forest litter (Fig. 10). The energetic balance was therefore more favorable to the old forest litter, indicating a better quality according to these thermal parameters. As the decomposition proceeded, a decrease in litter quality was found in both litters, but it was greater in the samples from the young stand, since a greater energy input (T50 for DTA) was needed to obtain a smaller energy output (J $\mathrm{mg}^{-1} \mathrm{OM}$ ).

\section{Discussion}

\section{Decomposition study through NMR}

During decomposition, the greater loss of C observed in the young forest litter could be related to the larger abundance of branched aliphatic chains and low molecular weight substances (such as amino acids), as revealed by the NMR spectra. In fact, these compounds are mainly responsible for the first phase of litter decomposition, since they are readily available to microorganisms and highly susceptible to mineralization and quick conversion to $\mathrm{CO}_{2}$ (Stout et al. 1988). Once the smaller and more easily accessible molecules have been degraded, the microcommunity is replaced by that which can degrade the more recalcitrant components such as lignin (Berg \& McClaugherty 2008). In both litters, the lignin signals in the NMR spectra were not visible, since the presence of cuticles and aliphatic components hampered the lignin dissolution in DMSO. However, after $\mathrm{CW}$ extraction and the consequent strong decrease in the amount of aliphatic components (especially cuticles and waxes), the lignin signals appeared well visible in the $\mathrm{CW}$ spectra, and their intensity was observed to decrease after the 9 months of decomposition. Therefore, according to thermal and NMR data, the lignin degradation can start at a very early stage of decomposition. On the contrary, the more complex and recalcitrant aliphatic region of cuticle and waxes were not attacked at the earliest stages, as they were still strongly present in both litters at the end of the study.

\section{Decomposition study through thermal analysis}

The loss of C (Tab. 1) during litter decomposition is the result of the breakdown of different organic constituents, such as watersoluble substances, polymer carbohydrates like hemicellulose and holocellulose, lignin and hydrophobic compounds such as lipids

The cellulose and lignin content in the litter estimated by the mass loss associated with EXO1 and EXO2 showed a weak correlation with their contents measured with the chemical method (Fig. 8). This discrepancy is due to the fact that the determination of cellulose and lignin by chemical methods was carried out on the $\mathrm{CW}$, while the thermal analysis was applied directly to the litter. Therefore, TG-DTA in this specific case and waxes (Berg \& McClaugherty 2008). is a direct measure of the different organic substances forming the litter itself and of their intimate connections and linkages making the complexity of the structure. In other words, when the thermal analysis is applied to litters, EXO1 and EXO2 are the result of the thermal degradation of cellulose, lignin and several other substances that are thermally degraded and contribute to determine the physical and chemical characteristics of litters. Indeed, when the thermal analysis was applied to $\mathrm{CW}$, the correlation between the two exothermic peaks and the cellulose and lignin content obtained by chemical method significantly improved (Fig. 8), even though these two litter constituents (particularly the lignin) were overestimated by the chemical method (Fig. 8, Tab. 2). It has been reported that the Klason's method causes condensation reactions during the extraction procedure, leading to an overestimation of the lignin content (Carrier et al. 2011, Jiang et al. 2010). The presence of proteins associated to $\mathrm{CW}$ can also contribute to the overestimation of the true lignin, since proteins may not be not completely hydrolysed during the cellulose digestion, thus they are included in the quantification of lignin (Montané et al. 2010).

The differences between the thermal behavior of litter and CW samples confirm that the extraction procedure affect the structure of the samples. The main effects were a shift of EXO1 and EXO2 peaks towards lower temperatures and the lack of the third exothermic peak related to the most recalcitrant organic compounds present in the litters. The shift of $30-40{ }^{\circ} \mathrm{C}$ that involved EXO1 highlighted a weakening of the cellulose structure. As reported by Yang et al. (2007), the proper cellulose is expected to react at a temperature range of $315-400{ }^{\circ} \mathrm{C}$ as we observed for the litter, whereas lower Tmax $\left(220-315^{\circ} \mathrm{C}\right)$, like those we found for the $\mathrm{CW}$, are reported by the same authors for structures simpler than that of the cellulose, such as hemicellulose. The EXO2 shifted towards lower temperature, suggesting a weakening of the chemical structure. However, the most evident effect of the extraction procedure was the absence of the third exothermic peak in the thermal profile of the CW. NMR data showed that these losses involve the aliphatic components, lipids and waxes forming the cuticle, which is eliminated by the extraction procedure. The presence of a third exothermic peak at around $500{ }^{\circ} \mathrm{C}$ was also observed by Rovira et al. (2008) in the decomposing litter of a Mediterranean pine forest, though it was associated with the presence of refractory products formed during degradation, since it was found only at the final stage of decomposition. On the contrary, in our study we considered this peak as related to litters components, since it was already present in the undecomposed litters. 
Although the amount of these extra-recalcitrant $\mathrm{C}$ components is small as compared with other constituents, their relative content significantly increased during the decomposition, and may affect the long-term degradation process.

\section{Quality litters changes during decomposition}

During decomposition, the quality of the decomposing litter, as a measure of its biodegradability by the soil microbial community, is expected to decrease as more recalcitrant substances tend to accumulate. The energetic approach recently introduced by Rovira et al. (2008) can give further perspective in the evaluation of the litter quality and its changes during decomposition, focusing on the energetic balance between the energy stored in the litter and the input needed to release it. Using this approach, a high input of energy needed to oxidize the litter (high recalcitrance) does not necessarily imply low quality, as the energetic benefit obtained by litter oxidation can be higher than the input Recently, the thermal parameters used to evaluate the litter quality were found to be well correlated to biological indexes of $\mathrm{OM}$ stability, in particular high energy content and high energy input indicate a high OM stability (Plante et al. 2011). According to this concept, the young forest litter was characterized by a lower quality and a higher stability than the litter form the old stand Nevertheless, we observed a faster degradation of young litter as compared with the old one. A possible explanation of such discrepancy can be that these thermal parameters link the measure of energy to the biochemical characteristics of the whole litter, but the different components can undergo selective biodegradation and this surely affects the rate of decomposition. A larger amount of thermolabile components were degraded in the young than in the old forest litter during the studied period. On the contrary, the more thermostable components were less affected by decomposition and tended to accumulate thus causing a decrease in litter quality as the decomposition proceeded. This behavior is in agreement with what reported by Ågreen \& Bosatta (1996) and in general with the classical view of the quality change during decomposition. The decrease in quality was more evident in the young forest litter as it contains components more thermostable than the old forest litter (Fig. 5).

In contrast with our results, Rovira et al. (2008) found an increase in litter quality during decomposition. However, the duration of their experiment was different as they considered five stages of decomposition with the latest reached when the litter had lost 60$65 \%$ of their initial mass. Furthermore, the litter of broadleaf species used in this study was characterized by a higher quality and was generally less recalcitrant to degradation than coniferous species.

\section{Conclusions}

The use of thermal analysis allowed tracing shifts in litter chemical structure and quality during a short decomposition period, giving qualitative and quantitative information on the main classes of organic compounds involved in the decomposition process. Thermal analysis highlighted changes in the litter structure and complexity, including components removed by the extraction procedure such as cuticles and waxes as showed by NMR data. Such more recalcitrant substances tend to accumulate and could influence the decomposition rate at later stages of the process. The good correlation between cellulose and lignin content obtained by chemical method and TG data of $\mathrm{CW}$ suggests that thermal analysis may be a useful tool to directly measure these litter components without further steps. Furthermore, the thermal analysis carried out has highlighted a better energetic balance of the old than the young forest litter, allowing to assess their quality based on their energetic balance.

Thermal analysis is a powerful technique with potential interest in litter decomposition studies as it provides both structural and energetic information on litter changes occurring during the decomposition process. However, further studies are needed to better understand the actual relationship between the energetic balance and the microbial growth and activity, particularly with respect to the maturation of the entire litter and potential addition of micro and macrofaunal organic constituents to the litter.

\section{References}

Aber JD, Martin M (2002). Leaf Chemistry 19921993. NASA's Accelerated Canopy Chemistry Program (ACCP), Oak Ridge National Laboratory, Oak Ridge, TX, USA. [online] URL: http:// daac.ornl.gov/ACCP/guides/leafchem.html\#3

Aber JD, Melillo JM (1982). Nitrogen immobilization in decaying hardwood leaf litter as a function of initial nitrogen and lignin content. Canadian Journal of Botany 60: 2263-2269. doi: $10.1139 / \mathrm{b} 82-277$

Aerts R (1997). Climate, leaf litter chemistry and leaf litter decomposition in terrestrial ecosystem: a triangular relationship. Oikos 79: 439-449. doi: $10.2307 / 3546886$

Ågreen GI, Bosatta E (1996). Quality: a bridge between theory and experiment in soil organic matter studies. Oikos 76: 522-528. - doi: 10.2307/ 3546345

Allen SE (1989). Chemical analysis of ecological materials $\left(2^{\text {nd }}\right.$ edn). Blackwell Scientific Publications, Oxford, UK, pp. 169-171.

Anghern-Bettinazzi C, Lüscher P, Hertz J (1988). Thermogravimetry as a method for distinguishing various degrees of mineralization in macromorphologically defined humus horizons. Zeit- schrift für Pflanzenernährung und Bodenkunde 151: 177-183. - doi: 10.1002/jpln.19881510305 Berg B, McClaugherty C (2008). Chemical constituents as rate-regulating: initial variation and changes during decomposition. In: "Plant litter. Decomposition, humus formation, $\mathrm{C}$ sequestration ( $2^{\text {nd }}$ edn)". Springer-Verlag, Berlin, Heidelberg, Germany, pp. 115-148. - doi: 10.1007/9783-540-74923-3 6

Beyer L, Deslis K, Vogt B (1998). Estimation of soil organic matter composition according to a simple thermoanalytical approach. Communication in Soil Science and Plant Analysis 29: 12771297. - doi: 10.1080/00103629809370026

Bianchi G (1995). Plant waxes. In: "Waxes: chemistry, molecular biology and function" (Hamilton RJ ed). The Oily Press, West Ferry, Dundee, UK, pp. 175-222.

Brinkmann K, Blaschke L, Polle A (2002). Comparison of different methods for lignin determination as a basis for calibration of near-infrared reflectance spectroscopy and implications of lignoproteins. Journal of Chemistry and Ecology 28: 2483-2501. - doi: 10.1023/A:10214840025 82

Carrier M, Loppinet-Serani A, Denux D, Lasnier JM, Ham-Pichavant F, Cancell F, Aymonier C (2011). Thermogravimetric analysis as a new method to determine the lignocellulosic composition of biomass. Biomass and Bioenergy 35: 298-307. - doi: 10.1016/j.biombioe.2010.08.067 Couteaux MM, Bottner P, Berg B (1995). Litter decomposition, climate and litter quality. Trends in Ecology and Evolution 10: 63-66. - doi: 10.10 16/S0169-5347(00)88978-8

Ferrari E, Francioso O, Nardi S, Saladini M, Dal Ferro N, Morari F (2011). DRIFT and HR MAS NMR characterization of humic substances from a soil treated with different organic and mineral fertilizers. Journal of Molecular Structure 998: 216-224. - doi: 10.1016/j.molstruc.2011.05.035

Flaig W, Beutelspacher H, Rietz E (1975). Chemical composition and physical properties of humic substances. In: "Soil Component: Organic Components" (Gieseking JE ed). Springer, Berlin, Germany, pp. 1-211. - doi: 10.1007/978-3-64265915-7 1

Francioso O, Ferrari E, Saladini M, Montecchio D, Gioacchini P, Ciavatta C (2007). TG-DTA, DRIFT and NMR characterisation of humic-like fractions from olive wastes and amended soil. Journal of Hazardous Materials 149: 408-417. doi: 10.1016/j.jhazmat.2007.04.002

Gallardo A, Merino J (1993). Leaf decomposition in two Mediterranean ecosystems of southwest Spain: influence of substrate quality. Ecology 74: 152-161. - doi: 10.2307/1939510

Hatakeyama T, Zhenhai IL (1998). Calibration of temperature and enthalpy. In: "Thermal analysis”. John Wiley and Sons Ltd, Chichester, UK, pp. 8-14.

Hatfield R, Fukushima R (2005). Can lignin be accurately measured? Crop Science 45: 832-839. - doi: 10.2135/cropsci2004.0238

Haw JF, Maciel GE, Schroeder HA (1984). Carbon-13 nuclear magnetic resonance spectrome- 
tric study of wood and wood pulping with crosspolarization and magic-angle spinning. Analytical Chemistry 56: 1323-1329. - doi: 10.1021/ ac00272a028

Hedenström M, Wiklund-Lindström S, Oman T, Lu F, Gerber L, Schatz P, Sundberg B, Ralph J (2009). Identification of lignin and polysaccharide modifications in Populus wood by chemometric analysis of 2D NMR spectra from dissolved cell walls. Molecular Plant 2: 933-942. doi: $10.1093 / \mathrm{mp} / \mathrm{ssp} 047$

Jackson ML (1985). Soil chemical analysis: advanced course $\left(2^{\text {nd }}\right.$ edn). Parallel Press, University of Wisconsin, Madison Library, WI, USA, pp. 58-60.

Jacob M, Viedenz K, Polle A, Thomas FM (2010). Leaf litter decomposition in temperate deciduous forest stands with a decreasing fraction of beech (Fagus sylvatica). Oecologia 164: 1083-1094. doi: 10.1007/s00442-010-1699-9

Jiang G, Nowakowski DJ, Bridgwater AV (2010). A systematic study of the kinetics of lignin pyrolysis. Thermochimica Acta 498: 61-66. - doi: 10.1016/j.tca.2009.10.003

Johnson CS (1999). Diffusion ordered nuclear magnetic resonance spectroscopy: principles and applications. Progress in Nuclear Magnetic Resonance Spectroscopy 34: 203-256. - doi: 10.101 6/S0079-6565(99)00003-5

Kelleher BP, Simpson MJ, Simpson AJ (2006). Assessing the fate and transformation of plant residues in the terrestrial environment using HRMAS NMR spectroscopy. Geochimica and Cosmochimica Acta 70: 4080-4094. - doi: 10.1016/ j.gca.2006.06.012

Kögel-Knabner I (2002). The macromolecular organic composition of plant and microbial residues as inputs to soil organic matter. Soil Biology and Biochemistry 34: 139-162. - doi: 10.1016 /S0038-0717(01)00158-4

Kosheleva YP, Trofimov SY (2008). Characteristics of the biochemical composition of plant litter at different stages of decomposition (according to thermal analysis data). Biology Bulletin 35: 64-69. - doi: 10.1134/S106235900801010X Kristensen E (1990). Characterization of biogenic organic matter by stepwise thermogravimetry (STG). Biogeochemistry 9: 135-159. - doi: 10.10 07/BF00692169

Meentemeyer B (1978). Macroclimate and lignin control of litter decomposition rates. Ecology 59: 465-472. - doi: 10.2307/1936576
Melillo JM, Aber JD, Linkins AE, Ricca A, Fry B, Nadelhoffer KJ (1989). Carbon and nitrogen dynamics along the decay continuum-plant litter to soil organic-matter. Plant and Soil 115: 189-198. - doi: 10.1007/BF02202587

Melillo JM, Aber JD, Muratore JF (1982). Nitrogen and lignin control of hardwood leaf litter decomposition dynamics. Ecology 63: 621-626. doi: $10.2307 / 1936780$

Montané $\mathrm{F}$, Romanyà $\mathrm{J}$, Rovira $\mathrm{P}$, Casals $\mathrm{P}$ (2010). Aboveground litter quality changes may drive soil organic carbon increase after shrub encroachment into mountain grasslands. Plant and Soil 337: 151-165. - doi: 10.1007/s11104-0100512-1

Montecchio D, Francioso O, Carletti P, Pizzeghello D, Chersich S, Previtali F, Nardi S (2006). Thermal analysis (TG-DTA) and drift spectroscopy applied to investigate the evolution of humic acids in forest soil at different vegetation stages. Journal of Thermal Analysis and Calorimetry 83: 393-399. - doi: 10.1007/s10973-0057292-5

Moorhead DL, Sinsabaugh RL (2006). A theoretical model of litter decay and microbial interaction. Ecological Monographs 76: 151-174. - doi: 10.1890/0012-9615(2006)076[0151:ATMOLD] 2.0.CO;2

Plante AF, Fernández JM, Leifeld J (2009). Application of thermal analysis technique in soil science. Geoderma 153: 1-10. - doi: 10.1016/j.geoderma.2009.08.016

Plante AF, Fernández JM, Haddix ML, Steinweg JM, Conant RT (2011). Biological, chemical and thermal indices of soil organic matter stability in four grassland soils. Soil Biology and Biochemistry 43: 1051-1058. - doi: 10.1016/j.soilbio.2011 .01 .024

Reh U, Kratz W, Kraepelin G, Angern-Bettinazzi C (1990). Analysis of leaf and needle litter decomposition by differential scanning calorimetry and differential thermogravimetry. Biology and Fertility of Soils 9: 188-191. - doi: 10.1007/BF 00335806

Rovira P, Kurz-Besson C, Couteaux MM, Vallejo VR (2008). Changes in litter properties during decomposition: a study by differential thermogravimetry and scanning calorimetry. Soil Biology and Biochemistry 40: 172-185. - doi: 10.10 16/j.soilbio.2007.07.021

Rovira P, Vallejo VR (2000). Evaluating thermal and acid hydrolysis methods as indicators of soil organic matter quality. Communication of Soil Science and Plant Analysis 31: 81-100. - doi: 10.1080/00103620009370422

Schultz T, Templeteon M, McGinnins G (1985). Rapid determination of lignocellulose by diffuse reflectance Fourier transform infrared spectrometry. Analytical Chemistry 57: 2867-2869. - doi: 10.1021/ac00291a027

Simpson AJ, Kingery WL, Shaw R, Spraul M, Humpfer E, Dvortsak P (2001). The application of $1 \mathrm{H}$ HR-MAS NMR spectroscopy for the study of structures and associations of organic components at the solid-aqueous interface of a whole soil. Environmental Science and Technology 35: 3321-3325. - doi: 10.1021/es010607v

Stout SA, Boon JJ, Spackman W (1988). Molecular aspects of the paetification and early coalification of Angiosperm and Gymnosperm woods. Geochimica and Cosmochimica Acta 52 (2): 405-414. - doi: 10.1016/0016-7037(88)90096-8 Trofimov SY, Emelyanenko VI (2000). Study of thermodynamic functions of soil organic matter in the course of its decomposition. Journal of Thermal Analysis and Calorimetry 62: 69-74. doi: 10.1023/A:1010106626873

Vallejo VR (1981). Evaluation of $\mathrm{C}: \mathrm{N}$ ratio as a parameter of $\mathrm{N}$ mineralization. Mitteilungen des Osterreichischen Bodenkundlichen Gesellschaft 47: 71-78.

Wershaw RL, Leenheer JA, Kennedy KR, Noyes TI (1996). Use of ${ }^{13} \mathrm{C}$ NMR and FTIR for elucidation of degradation pathways during natural litter decomposition and composting. I. Early stage leaf degradation. Soil Science 161: $667-$ 679. - doi: 10.1097/00010694-199610000-0000 4

Willker W, Leibfritz D, Kerssebaum R, Bermel W (1993). Gradient selection in inverse heteronuclear correlation spectroscopy. Magnetic Resonance in Chemistry 31: 287-292. - doi: 10.10 02/mrc. 1260310315

Wu DH, Chen AD, Johnson CS (1995). An improved diffusion-ordered spectroscopy experiment incorporating bipolar-gradient pulses. Journal of Magnetic Resonance, Series A 115 (2): 260-264. - doi: 10.1006/jmra.1995.1176

Yang H, Yan R, Hanping C, Ho Lee D, Zheng C (2007). Characteristics of hemicellulose, cellulose and lignin pyrolysis. Fuel 86: 1781-1788. doi: 10.1016/j.fuel.2006.12.013 